\title{
DA MENINA MEIGA À HEROÍNA SUPERPODEROSA: INFÂNCIA, GÊNERO E PODER NAS CENAS DA FICÇÃO E DA VIDA*
}

\author{
Raquel Gonçalves Salgado*
}

\begin{abstract}
RESUMO: Este artigo pretende discutir o desenho animado As meninas superpoderosas como um texto midiático que traz à tona a imagem da criança como herói. Analisamos os modos como crianças de uma turma de educação infantil interpretam episódios do desenho animado e, a partir dessas referências simbólicas, produzem sentidos sobre ser criança na contemporaneidade. Com base no diálogo entre os discursos das crianças e aqueles que compõem a narrativa da animação, discutimos os novos mapeamentos das fronteiras entre infância e vida adulta e das experiências masculina e feminina. Destacamos, também, os modos como as meninas produzem uma cultura lúdica, atravessada por referências advindas de outros textos midiáticos, nos quais a imagem da menina poderosa aparece associada à sedução. Por fim, refletimos sobre as contradições da infância contemporânea, situadas entre a desconstrução da imagem da criança frágil e inocente e outras formas de controle adultas, circunscritas pela cultura do consumo.
\end{abstract}

Palavras-chave: Infância. Gênero. Cultura midiática.

* Parte deste trabalho foi apresentada no VIII Encontro Nacional de Pesquisa em Educação da região Centro-Oeste (ANPEd Centro-Oeste), na Universidade Federal de Mato Grosso (UFMT), em Cuiabá.

** Doutora em Psicologia e professora adjunta de Psicologia da Educação do Campus Universitário de Rondonópolis, da Universidade Federal de Mato Grosso (UFMT). E-mail: ramidan@terra.com.br 
Da menina meiga à heroína superpoderosa...

FROM THE SWEET GIRL TO THE POWERFUL HERO:

CHILDHOOD, GENDER AND POWER IN THE FICTION AND LIFE SCENES

ABSTRACT: This article aims to discuss The powerpuff girls cartoon as a media text that brings the child image as hero. We analyse the ways preschool children interpret some cartoon episodes and, through these symbolical references, produce meanings about being a child in contemporary culture. Based on the dialogue between children discourses and those which compose the animation narrative, we discuss the new mappings of the boundaries between childhood and adulthood and between male and female experiences. We also highlight the ways girls produce a play culture, crossed by references taken from other media texts in which the image of the powerful girl appears associated with seduction. In conclusion, we analyse the contradictions of the contemporary childhood, located between the deconstruction of the fragile and innocent child image and other types of adult control, drawn by consume culture.

Key words: Childhood. Gender. Media culture.

\section{Introdução}

$\mathcal{D}$

iversas narrativas da esfera midiática têm retratado cenas que trazem as crianças como heróis, não mais investidos de poderes sobrenaturais, mas possuidores de saberes e competências indispensáveis para lidar com os desafios da vida contemporânea. São crianças que, por atestarem autonomia e, em muitas situações, prescindirem da presença adulta, desestabilizam a ideia da infância como o tempo da inocência e fragilidade (Salgado, 2003).

Diante dessas cenas, presenciamos fatos que escapam da ordem da ficção e se tornam experiências da nossa vida cotidiana e das relações que nós, adultos, tecemos com as crianças de carne e osso. Tais fatos apontam para a maleabilidade das fronteiras que, até então, delimitavam os tempos da infância e da vida adulta, gerando um novo mapeamento dos papéis e espaços sociais, ocupados por crianças e adultos, no cenário contemporâneo.

Nas interfaces entre as cenas midiáticas e as cenas da vida cotidiana, temos como mote a reflexão sobre os diálogos que as crianças 
"reais" estabelecem com as outras crianças que habitam o mundo virtual, construindo valores, conhecimentos e experiências que se traduzem em culturas lúdicas tecidas com as referências simbólicas extraídas da cultura mais ampla. Para tanto, trazemos à tona o desenho animado As meninas superpoderosas, cujas heroínas são três meninas pequeninas. Trata-se de um texto midiático que, além de desestabilizar as fronteiras entre a infância e a vida adulta, rompe com os atributos tradicionalmente destinados às experiências masculina e feminina, dando visibilidade à representação da menina poderosa, que ofusca a imagem da menina frágil e ingênua.

As reflexões que aqui ganham corpo têm sua origem em uma pesquisa desenvolvida com 21 crianças de 5 a 6 anos de uma turma de educação infantil, ${ }^{1}$ sendo seis meninos e quinze meninas. Por apresentar um caráter de intervenção, a abordagem metodológica da pesquisa inclui a realização de oficinas que se constituem como espaços de reflexão e discussão coletiva sobre a mídia televisiva, uma vez que destas participam crianças, professoras e pesquisadora. Nessas oficinas, episódios de desenhos animados contemporâneos - entre eles As meninas superpoderosas são assistidos e postos em discussão pelo grupo. Além disso, com a câmera de vídeo digital, filmamos diversas situaçóes das crianças brincando na sala de aula ou no pátio. Foram selecionadas brincadeiras em que as crianças trazem como tema o desafio à visão adulta da fragilidade e inocência infantis, de modo a compor uma edição de imagens que é objeto de reflexão e debate na turma. Nesse sentido, a videogravação se define, no contexto desta pesquisa, como um recurso tecnológico que se presta tanto à coleta de dados, ao permitir o registro das brincadeiras, quanto à instauração de reflexões e debates entre crianças e adultos sobre as experiências que se materializam em imagens.

As fronteiras entre infância e vida adulta na contemporaneidade

Desde a metade do século XX, temos experimentado intensas transformações na esfera da cultura, das relações sociais, da produção de valores e conhecimentos e dos modos de subjetivação. Estamos imersos na era tecnológica e pós-industrial, marcada por reflexões que põem em xeque paradigmas que até então serviam de suporte aos grandes sistemas de conhecimento da humanidade, como a filosofia, 
Da menina meiga à heroína superpoderosa...

as ciências, as religióes e as artes. Tais reflexões caracterizam o que autores como Lyotard (1998) e Jameson (1993), entre outros, denominam de pós-modernidade, terreno fértil para as experiências culturais vividas no final do século e para a emergência de conceitos e valores que desestabilizam certezas antes consolidadas. É, também, nesse contexto que podemos assistir, de forma mais visível, ao esfacelamento das fronteiras entre as gerações. Os papéis convencionais atribuídos ao adulto e à criança deixam de ser tão estáveis. Se outrora a criança era vista como um ser marcado pela ingenuidade, fragilidade e incompetência, cujo desenvolvimento dependia estritamente do controle adulto, através de uma educação pautada na disciplina e moralização, hoje ela assume o lugar de protagonista, alvo privilegiado da sociedade de consumo. Se outrora a família e a escola eram instituições privilegiadas para a socialização e a educação das crianças, hoje elas contam com o aporte da mídia eletrônica, com a qual as crianças têm mantido estreitas relaçóes, que envolvem aprendizagens, desenvolvimento e construções identitárias.

Ao analisar a relação entre crianças e adultos no mundo contemporâneo, Postman (1999) afirma que, com o advento da televisão, na segunda metade do século XX, as fronteiras entre infância e idade adulta, ao invés de se enrijecerem, foram definitivamente corroídas. Desaparecia, assim, a ideia moderna de infância. ${ }^{2}$ Para ele, enquanto a prensa tipográfica cria condições necessárias para o delineamento da linha divisória entre as geraçôes, já que os adultos precisam formar e preparar as crianças para ingressar no mundo adulto, a mídia televisiva tem acirrado a degeneração dessas fronteiras, ao não requerer de seu público formação ou preparação para compreender seus signos ou promover segregações. Com a televisão, os segredos, antes preservados, agora são difundidos e deles compartilham crianças e adultos. Família e escola perdem seus papéis de regulação do desenvolvimento infantil e, assim, a autoridade adulta se esvai. Adultos e crianças, diz Postman (op. cit.), se transformam: os adultos são infantilizados, ao passo que as crianças se tornam precocemente adultas.

Nas cenas da vida cotidiana, temos nos deparado com crianças que não mais se reconhecem como inocentes ou frágeis e desafiam a delimitação do tempo da infância para compartilhar os signos da cultura midiática, que devastam as fronteiras etárias. São crianças que, com 
canções, danças, roupas e trejeitos, provam ter condições e requisitos para ingressar e participar dessa cultura, antes definida como exclusiva do mundo adulto, e, assim, vão compondo os sentidos da infância. Por outro lado, temos crianças e adultos - distantes e, ao mesmo tempo, próximos - que se confrontam com imagens da infância que não mais retratam suas relaçóes e experiências cotidianas. Fronteiras rígidas que separam crianças e adultos vão se tornando instáveis, ao ponto de não mais se sustentarem. Diante disso, nos perguntamos: $\mathrm{O}$ que significa ser criança no mundo contemporâneo? Como as experiências da infância são definidas e caracterizadas diante da cultura midiática?

Estamos diante de muitas tensões e contradições que atravessam não apenas o debate teórico, mas as experiências que configuram a infância na contemporaneidade. Buckingham (2000) retrata e discute essas tensões, mostrando que, se, por um lado, há os que olham com pesar para a relação entre a criança e a mídia televisiva, como Postman (1999) e Steinberg e Kincheloe (2001), por outro, há aqueles que admitem o fato de que as gerações mais jovens são mais competentes do que a geração de adultos, no que se refere ao uso das novas tecnologias, como Tapscott (1998), Papert (1980, 1993, 1996), Katz (1993, 1997) e Rushkoff (1996). ${ }^{3}$ Ambas as posições teóricas, afirma Buckingham, apontam para visões essencialistas de criança, do adulto, da mídia e da relação entre esses três elementos, além de tratarem as gerações como homogêneas. $\mathrm{O}$ autor destaca que as fronteiras entre crianças e adultos são desenhadas e redesenhadas, ao passo que a arena simbólica em que estas se constituem também vai assumindo novas facetas. Definir categoricamente o que pertence ao mundo da infância e ao mundo adulto significa tratar as experiências e relações entre crianças e adultos como acontecimentos apartados das transformaçóes que movimentam a vida social e cultural. A ideia do desaparecimento da infância na cultura contemporânea, defendida por Postman (op. cit.), carrega conceitos de infância e vida adulta que se fixam às práticas culturais do tempo em que são forjados. A ausência de segredos e pudor na relação entre crianças e adultos, o convívio e o envolvimento das crianças com assuntos como violência e sexo, ao mesmo tempo em que derrubam as fronteiras antes erguidas entre a infância e a vida adulta, apontam para outras configurações desses mundos. Diante das experiências e práticas sociais que hoje crianças e adultos compartilham, há muito mais a construção de outros sentidos e imagens sobre a infância do que sua derrocada. As relações estabelecidas 
Da menina meiga à heroína superpoderosa...

entre crianças e adultos, em cada tempo e cultura, criam e são responsáveis por modos de definir, representar e demarcar fronteiras entre a infância e a vida adulta.

Há, além dos aspectos já abordados, outros elementos que acirram o caráter contraditório da infância contemporânea. Se, por um lado, a criança assume lugar de destaque na esfera do consumo e da mídia eletrônica, por outro, está submetida ao controle e à vigilância dos adultos, aqueles que, ainda, detêm o domínio absoluto sobre a produção midiática dirigida às crianças (Buckingham, 2000). Temos uma mídia para crianças produzida por adultos, afirma Buckingham (op. cit.), diante do fato de que são eles, em última instância, que tecem os discursos que circulam nessa esfera a partir de suas representações de infância e vida adulta.

No trabalho sobre Peter Pan, Jacqueline Rose (1984 apud Buckingham, 2002) mostra como a audiência infantil é definida, ainda que de maneira implícita, pelos adultos. A autora afirma que os programas televisivos dirigidos às crianças não devem ser vistos apenas como representações dos desejos e das fantasias infantis, mas como textos que também carregam os desejos e fantasias dos próprios adultos. Por serem discursos através dos quais os adultos definem e regulam sua relação com as crianças, as narrativas televisivas, além de se dirigirem a elas e se preocuparem com o que querem e desejam, apontam para as expectativas e demandas do mundo adulto em relação à infância.

Não podemos escapar de uma reflexão sobre a criança que não seja atravessada por uma compreensão do adulto, de suas representações sobre infância e de suas relações com a criança. Infância e vida adulta são categorias que, segundo Mayall e Zeiher (2003), estão fortemente interligadas, de modo que não há como uma sobreviver sem a outra. Mudanças na infância provocam mudanças na vida adulta e vice-versa. É nesse sentido que as posturas extremas ou essencialistas sobre a infância contemporânea, ao congelarem tanto a criança quanto o adulto, não consideram as diversas infâncias com que nos deparamos pelo mundo afora e as alteraçôes que a cultura, a história, as condições econômicas e sociais não cessam de provocar nos modos de ser criança e adulto. Refletir sobre a cultura infantil significa atentar-se para a relação entre crianças e adultos, uma vez que os discursos sobre a infância remetem, também, a formas de situar o adulto na vida social (Bazalgette \& Buckingham, 1995). 
Longe das posturas radicais, pretendemos aqui desenvolver uma reflexão sobre a infância contemporânea e suas mediações com a mídia que tenha como pano de fundo as relações que crianças e adultos estabelecem entre si, suas negociações, as fronteiras que se delineiam e se desfazem entre esses dois mundos, que, estando próximos ou distantes, não deixam de manter estreitas relações.

No mundo contemporâneo, experiências sociais e culturais, atravessadas pela mídia e o consumo, têm provocado nas crianças outras formas de desenvolvimento e aprendizagem, fortemente marcadas por diálogos com as outras crianças do mundo virtual, que têm como características marcantes a autonomia e o desafio à tutela adulta. Entre elas, estão os pequenos heróis dos desenhos animados, com os quais as crianças do "mundo real" têm construído valores e outros modos de conhecer e perceber o real, na rede contemporânea que entrelaça o universo da imagem técnica ao das relaçóes humanas.

\section{As meninas superpoderosas: doces e meigas, destemidas e sagazes}

Lindinha, Florzinha e Docinho são As meninas superpoderosas e protagonistas do desenho animado de mesmo nome, produzido, veiculado e distribuído a outras emissoras de televisão pelo Cartoon Network. ${ }^{4}$ Seu criador é o norte-americano Craig McCracken, considerado como um dos animadores de destaque da cultura infantil contemporânea, devido ao sucesso da série entre crianças de todo o mundo. A história do desenho animado trata das façanhas de três meninas pequeninas, da cidade de Townsville, geradas a partir de uma experiência genética realizada pelo professor Utônio, cientista de um centro de pesquisa e a referência paterna das crianças. No instante em que o professor está envolvido com a experiência de gestação artificial das meninas, seu assistente de laboratório, um macaco, derrama acidentalmente uma substância química, chamada "Elemento X", fazendo com que as crianças nasçam com superpoderes. Como as grandes heroínas de sua cidade, as pequeninas combatem diariamente o crime organizado pelos monstros criados pelo Macaco Loco, ex-assistente do professor, que se torna o maior inimigo das meninas por ter sido rejeitado quando elas nasceram.

O desenho animado entra na pesquisa como uma das narrativas midiáticas que suscita questóes e provoca o debate entre crianças e 
Da menina meiga à heroína superpoderosa...

adultos. Nesse diálogo, as crianças se posicionam e revelam os modos como interpretam e atribuem sentido ao enredo e aos personagens que compóem a trama do desenho animado.

Raquel: "E vem cá, as meninas têm pai, têm mãe?”.

Alexia: "Não. Só tem pai".

Raquel: "E quem é o pai?".

Alexia: "É o professor".

Raquel: "Como é que elas têm poderes se elas são meninas tão pequenininhas?”.

Gustavo: "Porque elas conseguem dar porrada de pé, de mão e de cabeça".

Raquel: “Ah, é?! Mas, uma menina pequenininha daquele jeito consegue fazer tanta coisa assim?".

Crianças: "Consegue".

Alexia: "Elas nasceram com, com poderes".

Raquel: "Ah, é? Elas já nasceram assim lutando?"

Alexia: "Porque o professor, ele, sem querer, ele quebrou o, o, a poção X, aí, ele, aí, elas ficaram, aí, elas terminaram virando Meninas Superpoderosas e com os poderes".

Meninas, poderosas de nascença e por acidente, com um professor-pai, cuja experiência científica as trouxe ao mundo. Assim são as meninas superpoderosas na versão das crianças e é com essa explicação que elas significam a identidade contraditória das heroínas contemporâneas: meninas pequeninas, porém fortes e valentes, que dão "porrada de pé, de mão e de cabeça”, porque nasceram com superpoderes.

Essa suposta contradição também é tratada por Potts (2004), ao analisar a série de animação, que discute a emergência da temática das meninas heroínas como forma de atribuição de poder às mulheres e às crianças em geral. Combinando feminilidade com coragem, aventura e heroísmo, o desenho animado, na visão da autora, problematiza a ideia da impossibilidade de coexistência de características adequadas ao estereótipo feminino, como doçura, meiguice e inocência, com força e poder, características culturalmente associadas à virilidade. Florzinha, Lindinha e Docinho provam, com suas atitudes e feitos heroicos, ser 
possível conjugar força, poder, ternura, delicadeza e, em alguns momentos, fragilidade. Com isso, o desenho animado desmistifica os estereótipos associados aos sexos, diluindo as fronteiras estanques entre ser masculino, como expressão de força, coragem e poder, e ser feminino, como expressão de fragilidade e sensibilidade. Além disso, recusase a retratar o poder feminino como decorrente de atributos sexuais, visto que as meninas são poderosas sem serem obrigatoriamente sensuais, como muitos outros textos midiáticos fazem questão de explorar.

Gustavo: "Só quem não tem medo de nada é o Docinho".

Raquel: "Docinho! Você acha que a Docinho é a mais corajosa?".

Crianças: "É".

Amanda: "A verde é a mais corajosa. As outras só ficam apaixonadas".

Raquel: "Só ficam apaixonadas?!".

Amanda: "É".

Raquel: "E as que ficam apaixonadas não são corajosas?”.

Amanda: "Não, são. Mas, elas só ficam sorrindo".

Raquel: "E a que não fica sorrindo, ela faz o quê?".

Amanda: "Ela luta".

Ser corajosa e ficar apaixonada, sorrir e lutar são atributos que, embora estejam reunidos para compor a identidade das meninas poderosas, se tornam incompatíveis quando se trata do perfil da menina mais corajosa. Na opinião das crianças, essa menina é Docinho, a verde, que não fica apaixonada e tampouco sorri, mas luta e tem muita coragem. Mesmo que o desenho animado pretenda romper com estereótipos que demarcam a experiência feminina e a masculina, como mostra Potts (op. cit.), as crianças, meninos e meninas, apontam contrastes entre os personagens que reavivam esses estereótipos. O modo como as crianças definem Docinho dá visibilidade a fronteiras rígidas que são reerguidas para a demarcação de gênero. Apesar de ser menina, Docinho é vista como o menino do trio. Essa confusão é tão nítida a ponto de Gustavo a ela se referir como o Docinho. Também é ela quem, na visão das crianças, nada teme, não fica apaixonada, não sorri e não luta. Docinho, de fato, preenche esses requisitos. Talvez nela, a força, a coragem e o poder sejam tão 
Da menina meiga à heroína superpoderosa...

marcantes que apagam ou escondem sua meiguice e doçura, embora carregue esse atributo no nome. ${ }^{5}$

Para além das oposições binárias, que demarcam o masculino como território da virilidade e da força e o feminino como sinônimo de sensibilidade e fragilidade, há que se pensar no gênero, diz Scott (1995), como uma arena de relações sociais entre os sexos que definem construções identitárias e culturais. Nessa perspectiva, o gênero remete a uma categoria social que estabelece distinções a partir dos papéis sexuais atribuídos a homens e mulheres. Papéis estes que se fazem e refazem por estarem imersos no fluxo dos sistemas de significação ancorados na história e na cultura (Scott, op. cit.). $\mathrm{O}$ desenho animado, por sua vez, propõe essa redefinição de papéis ao abrir espaços para a reflexão sobre outros modos de significar as experiências masculina e feminina na cultura contemporânea.

Outro aspecto levantado por Potts (2004) é o fato de as meninas serem crianças comuns, que estão envolvidas e se preocupam com coisas que fazem parte da vida cotidiana de crianças pequenas como elas, tais como ir à escola todos os dias, fazer tarefas domésticas e escolares e ter horário marcado para dormir. Entretanto, por serem heroínas, precisam conciliar a agenda de uma menina comum com o combate ao crime na cidade de Townsville, missão que, às vezes, as afasta de suas atividades cotidianas.

Rita:6 "Já pensou, já pensou se vocês também ao invés de ter casa, vocês só tivessem a professora Suzana? Não é a mesma coisa? Aí, vocês não iam voltar pra casa. Era a Suzana que ia fazer tudo pra vocês".

Menina: “Ah, mas é só no desenho!”.

Rita: "Ah! É só no desenho. Achei que era de verdade. Achei que de verdade conseguia ficar...".

Menina: "Mas as meninas superpoderosas, ah, é... mora de verdade, pra casa. Ela vive de verdade".

Menina: "É. Deve ser adotiva”.

Menina: “(...) Ela vive de verdade, mas é muito longe daqui. Ela mora nos...".

Rita: "Eu nem sei quem são os pais delas".

Menina: "Nem eu". 
Rita: "E elas moram onde?".

Alexia: "Em casa".

Rita: "Em casa? Como será que é a casa delas?”.

Tuany: "É igual a minha".

Criança: "A minha também".

Rita: “Como é que é? É uma casa bonita?”.

Crianças: "É".

Rita: "E elas moram com quem? Moram elas três?".

Crianças: "Com o professor".

As crianças veem as meninas, ainda que poderosas, como crianças comuns, muito próximas às crianças de carne e osso do "mundo real". Nesse estreitamento de laços entre a ficção e a vida cotidiana, dois movimentos são possíveis: os personagens aproximam-se da vida ordinária, deixando de ser tão fantásticos e irreais, e a ficção penetra com mais intensidade na experiência cotidiana, ao passo que a identificação com esses personagens se acentua. As crianças, além de apontarem para as semelhanças entre a vida das meninas no desenho animado e o que se passa em suas próprias vidas, conferem às pequenas heroínas materialidade, ainda que as preservem como personagens da ficção. A narrativa e os personagens dos desenhos animados são elementos que participam, cada vez mais, da vida real de crianças no mundo contemporâneo, à medida que ganham vida em objetos, roupas, brinquedos e outros textos, atenuando as fronteiras entre a ficção e o real.

A relação entre crianças e adultos é outro forte viés dos episódios da série. As transformações por que passam crianças e adultos na cultura contemporânea são fortes ingredientes do desenho animado. "Oh, Dynamo" é um dos episódios da série que trazem à tona essa questão, eleito para ser assistido e debatido nas oficinas de tevê realizadas na pesquisa. Olhando para as meninas como crianças indefesas e vulneráveis aos perigos e ameaças a que estão expostas todos os dias por causa de suas missões heroicas, o professor decide tomar providências para salvar suas vidas. Ao presenciar as meninas enfrentando um monstro-peixe enorme, ele se desespera com a possibilidade de perdê-las. 
Da menina meiga à heroína superpoderosa...

Professor: “Ah, meninas! Pensei que fosse perder vocês!”.

Docinho: "Ah, qualé! Não seja bobo! Somos meninas superpoderosas e o que temos que fazer é combater o crime e monstros gigantes".

Ele decide, então, construir Dynamo, um robô gigante, para proteger as meninas dos riscos que correm ao defender a cidade de Townsville. Convictas de que não precisam de suporte para arcar com suas responsabilidades de heroínas, as meninas ignoram a armadura robótica construída pelo professor, mantêm intactas suas agendas de combate ao crime e nunca recorrem a Dynamo. Ao vê-las feridas e derrotadas após um novo confronto com o monstro, o professor ordena que Dynamo seja usada por elas imediatamente. Contrariadas, mas vendo-se obrigadas a atender à ordem do professor, as meninas assumem o comando do robô para enfrentar o monstro. Finalmente, Dynamo vence a batalha, mas a cidade fica totalmente destruída e reduzida a destroços. Tanto o prefeito quanto a população de Townsville, embora gratos à destruição do monstro, ficam indignados com o estado lastimável em que a cidade se encontra. As meninas, por sua vez, não medem palavras para acusar o professor, apontando-o como o verdadeiro culpado por toda aquela destruiçãa, já que as obrigou a usar o robô. $\mathrm{O}$ professor envergonha-se ao perceber seu erro e foge de cena, sem nada dizer.

Mais do que um duelo entre meninas com poderes e monstros gigantescos, o que esse episódio retrata é um confronto entre valores e representações de infância assumidas por crianças e adultos na cultura contemporânea. A experiência infantil, nas cenas da vida cotidiana, há muito, já não atesta mais a validade de uma imagem da infância como reino da inocência e fragilidade. Nessas cenas, não são apenas novas imagens sobre as crianças que se configuram, mas também outras representaçôes dos adultos e de seus lugares sociais na relação com elas. O episódio põe em xeque a estabilidade e rigidez dos papéis convencionais atribuídos a esses sujeitos. O professor, no lugar de pai, vê-se no compromisso de proteger, zelar pelo bem-estar das meninas e fazer valer sua autoridade na relação com elas. As meninas, por outro lado, se rebelam contra o discurso da fragilidade infantil, que legitima os atos de cuidado e proteção do professor, recusando-se a serem vistas e tratadas como vulneráveis e indefesas. A autonomia das meninas e o fato de serem cidadãs responsáveis pela 
vida de sua cidade caminham na contramão do protecionismo adulto, reacendido pelo professor. Limites, regras de conduta, autoridade e, até mesmo, proteção são conceitos e experiências que se alteram quando são confrontados, em uma relação de alteridade, com o olhar e a experiência que vêm do outro. É possível ver, nas brechas desse texto midiático, um convite para que crianças e adultos olhem para suas relaçóes cotidianas como espaços propícios à criação de outros modos de ser e de se relacionar com o outro, que estejam abertos às experiências subjetivas e culturais construídas por ambos, ao invés de estarem aprisionados em valores e conceitos prontos de antemão.

De As meninas superpoderosas a Baba Baby: a imagem da meninamulher sedutora na composição de uma cultura lúdica feminina

Muitos são os discursos e práticas sociais que contribuem para a emancipação e a confrontação com o poder masculino, expressos nos modos de ser e agir de meninas no mundo contemporâneo. Para melhor compreendermos esse fenômeno, cabe aqui ressaltar, como faz Kehl (2001), que os lugares masculinos e femininos não se confundem com os lugares ocupados por homens e mulheres nos mais diversos grupos sociais. A circulação cada vez mais intensa desses lugares sociais, retratada em As meninas superpoderosas, tem também contribuído para a manifestação de um fato marcante na cultura ocidental contemporânea, que é a conquista das mulheres por espaços e papéis de destaque no cenário social, cultural e econômico. Ser mulher, nos tempos atuais, não significa mais estar restrita às tarefas domésticas, como cuidados com a prole, asseios do lar e dedicação ao cônjuge. Atualmente, as mulheres têm ocupado cargos de relevância social, ampliando sua inserção no mercado de trabalho e na vida social como um todo. A vida pública, há muito tempo, deixou de ser um mistério para elas, posto que é também nessa esfera que têm se confrontado com barreiras, edificadas em valores centrados no poder masculino, alargado fronteiras entre os sexos e construído novos mapeamentos da experiência feminina, que dizem respeito a outros modos de ser e agir como mulher na cultura atual.

As meninas, em suas incursões pela mídia, capturam textos que conjugam conquista, sedução, beleza e sensualidade com poder. Tomando esses textos como suas principais referências, as meninas, em 
Da menina meiga à heroína superpoderosa...

sala de aula, assumem o "palco", dublando, cantando, dançando e imitando Kelly Key e as cantoras do grupo Rouge, uma banda pop de grande sucesso da época.

Basta a professora colocar o CD para que a maioria das meninas faça da sala de aula o palco de um programa de auditório, cenário que se completa com a câmera que utilizamos para filmá-las. No início, é visível a disputa pela mira da câmera porque todas querem ser bem focalizadas ao mesmo tempo. Em seguida, elas percebem que um bom desempenho na dança exige espaço e, então, vão, aos poucos, ocupando a sala de aula, de tal forma que os meninos ficam restritos aos cantos da sala, sentados à distância do show. Há aqueles que permanecem de cabeça baixa e outros que chegam a tampar os ouvidos como forma de protesto contra as músicas.

Entre uma canção e outra, é possível perceber a preocupação de algumas meninas com suas parceiras, no intuito de comparar movimentos, gestos e performances. Elas se autoavaliam, tomando a outra como referência, enquanto a dança acontece. $\mathrm{O}$ mais importante é a performance, que não pode ser a que todos conhecem, pois se faz necessário agregar algo novo na repetição - um olhar, um sutil levantar de ombros, de sobrancelhas, um charme a mais faz a diferença. Como diz Vygotsky (1991), até mesmo na imitação é necessário estar de posse dos meios que permitem passar do já conhecido à novidade. Por isso, imitar não significa repetir mecanicamente. A forma como se apropriam dos gestos - os mais sutis -, trejeitos, caras, bocas e olhares das cantoras denuncia o trabalho e o investimento envolvidos na composição das performances. De Baba Baby a Assererrê, ${ }^{7}$ as meninas vão, com a mistura de gestos sensuais e atitudes imponentes, comunicando a história que a letra das músicas revela.

Mais do que uma simples imitação das danças ou reprodução das cançôes, o que há é um engajamento das meninas na cultura pop que abarca todas essas manifestações. Esse envolvimento implica a construção de uma cultura lúdica, tal como Brougère (1995, 1998) a define, ${ }^{8}$ na medida em que as meninas retiram da vida social elementos simbólicos que vão compor as práticas sociais, os valores, as representações e as regras que ganham vida nos modos como transformam as danças e as canções de Kelly Key e do grupo Rouge em brincadeiras. 
Ao dialogarmos com as crianças sobre o vídeo em que as meninas cantam e dançam Baba Baby e Assererrê, elas definem o que é ser uma criança normal na cultura contemporânea.

Raquel: "Como é que é aquela história: 'Eu cresci, agora não sou mais uma menina...'. Não tem uma coisa assim?”.

Raquel: "Essa música é pra criança ou é pra gente grande?”

Menina: "Criança".

Menina: "Pros dois".

Raquel: "Pros dois? Por que que é pra criança também?”.

Alexia: "Oh, tia, sabia que eu vi um dia na 'Eliana'. Ele falava que essa história que eles estão cantando era só pra adolescente, para adultos. Mas as crianças gostaram da história, aí ficou pra todo mundo. Aí, ficou assim mesmo".

Bianca: "E a Kelly Key serve pra todo mundo".

Raquel: "É uma dúvida que eu tenho, é dúvida mesmo porque eu não sou mais criança. $\mathrm{Na}$ minha época, quando eu era criança, a gente só cantava: 'Atirei o pau no gato, to, to...', não é Rita? Não é Suzana? [As meninas começam a rir]. Eu quero saber por que as crianças hoje gostam da Kelly Key e do Rouge?".

Meninas: "As crianças gostam mais da dança, da música".

Raquel: "E 'Atirei o pau no gato', 'Ciranda, cirandinha'? Qual é a música melhor?".

Menina: "Essa aí é pra gente muito pequenininha".

Raquel: "Então, quer dizer que vocês hoje são meninas bem mais as$\operatorname{sim} . . . ”$.

Menina: "Mais bonitas".

Raquel: “... Mais bonitas, avançadas e modernas porque gostam...”.

Meninas: "É. Eu sou".

Menina: "Eu sou normal”.

Raquel: "É normal uma menina gostar da Kelly Key?”.

(As meninas começaram a discutir se era ou não normal gostar da Kelly Key). 
Da menina meiga à heroína superpoderosa...

Kelly Key representa a menina-mulher, um misto de sedução com ingenuidade, que, investida de poder, não se subordina ao poder masculino. Além disso, faz emergir a imagem da menina experiente e precocemente sexualizada, que ameaça e desafia a concepção normativa de uma infância naturalmente ingênua e afastada do mundo adulto. Por outro lado, uma nova normatização se instaura com o aval do discurso midiático, que passa a ser o parâmetro para definir as competências e experiências válidas para uma criança se engajar na cultura de seu tempo, já que, na declaração das meninas, gostar de Kelly Key é a expressão de uma infância normal.

$\mathrm{Na}$ tentativa de compreender o lugar da cultura popular no processo de constituição da subjetividade feminina e, sobretudo, da subjetividade das meninas, Walkerdine (1997) analisa como a mídia as retrata e como elas têm se relacionado com a cultura popular de seu tempo. Aponta como a representação midiática da menina esperta, experiente, maliciosa e precocemente sexualizada, que aparece sob o rótulo de heroína, se constitui como ameaça e desafio à concepção normativa de uma infância naturalmente ingênua e afastada do mundo adulto. Ao debruçar-se sobre como as meninas apropriam-se desses ícones da cultura popular feminina, Walkerdine (op. cit.) recusa-se a olhar para a questão da erotização, aspecto relevante nesse processo de apropriação, como um fenômeno que se restringe à perda da infância. Assim, identifica fama, talento e sucesso como elementos que também participam dos modos como as meninas se apropriam dos signos midiáticos e que podem significar, para elas, tanto uma forma de afastar-se da visão de criança ingênua e tutelada, quanto um mecanismo de ascensão social.

A figura da menina-mulher, assumida por Kelly Key, que atravessa as fronteiras entre as geraçóes, traduzindo, como afirma Walkerdine (1997), a mistura da mulher experiente com a menina inocente, é, sem dúvida, uma imagem da experiência feminina que vai de encontro aos movimentos de emancipação e redefinição de lugares e papéis sociais realizados por mulheres e meninas na cultura contemporânea. Em se tratando das meninas, essa imagem também se confronta com a concepção tradicional da criança frágil e inocente, o que desperta nelas um fascínio mobilizado pela necessidade de romper com as redomas impostas por essa concepção. 
Entre ser menina e poderosa: os dilemas da infância contemporânea

O paradoxo em torno da imagem da menina poderosa, tecida e realçada por diversas narrativas que compõem hoje a cultura midiática, é um dos fenômenos do nosso tempo que carregam as contradições vividas pela infância contemporânea. Se, por um lado, fronteiras rígidas entre os mundos infantil e adulto têm sido derrubadas, permitindo a construção de outros modos de conceber e interagir com as crianças, pautados em relaçôes menos hierárquicas e geradores da autonomia crescente que as crianças têm manifestado, por outro, novas barreiras têm sido interpostas entre esses mundos, de modo a produzir outras formas de controle e tutela adultas. $\mathrm{Na}$ condição de alvo privilegiado da cultura do consumo, a criança, agora consagrada como herói e protagonista, destaca-se e liberta-se, cada vez mais, das amarras de saberes e práticas adultas, que antes insistiam em denominá-la como um ser frágil, indefeso e inocente. Todavia, ela convive com outras amarras, agora ditadas pelo mercado, que, com seus objetos, imagens e textos, habita sonhos, fantasias e desejos e administra seu universo lúdico, ditando regras para brincar, jogar e compor sua cultura lúdica.

Além disso, na figura da menina-mulher, discurso que atravessa o enredo das cançôes e a linguagem dos corpos nas danças da cultura pop feminina de nossa era, deparamo-nos também com a imagem da menina sedutora, objeto sexual e alvo de uma cultura que explora esse paradoxo ao máximo, traduzindo-o em mercadoria. Não é à toa que, no mundo infantil feminino contemporâneo, são cada vez mais remotas as chances de encontrarmos roupas, sapatos, acessórios, bonecas e brinquedos que não façam apelo à aquisição dessa imagem. Acoplada a cada produto está a imagem da menina-mulher, que convida todas as outras meninas a participarem da vasta rede em que esta se constitui, ganha vida e sentido. Resta-nos saber até que ponto assumir essa imagem não se traduz em dilema para as meninas contemporâneas, divididas como estão entre uma infância, que escapa dos apelos de sedução e sensualidade, e outra infância, que é erotizada e desenhada pelo mercado.

Tais questōes se colocam diante de nós como desafios que nos convidam à construção de práticas culturais e educativas, assentadas em posturas e valores estéticos que possam trazer contrapartidas a 
essa ética ditada pelo mercado. Apontamos, neste trabalho, o quanto nós, pais e professores, há muito já deixamos de ser, no cenário contemporâneo, autores ou responsáveis exclusivos pela educação das crianças. Deparamo-nos com um projeto educativo dedicado a formar a atual geração de crianças, cujos mestres e didática pulverizam-se sob a forma de brinquedos, desenhos animados, filmes, revistas, canções, danças e uma série de outros produtos culturais, que se reúnem para compor uma rede de signos disponíveis ao consumo, conjugando entretenimento e educação.

\section{Notas}

1. Esta pesquisa deu origem à minha tese de doutorado, intitulada Ser criança e herói no jogo e na vida: a infância contemporânea, o brincar e os desenhos animados, defendida no Programa de Pós-Graduação em Psicologia Clínica, da Pontifícia Universidade Católica do Rio de Janeiro (PUC-Rio), em 2005. Seu principal objetivo foi compreender, nas experiências lúdicas das crianças, os valores que elas constroem ao interagirem com os personagens e as histórias extraídas dos desenhos animados contemporâneos, e como esses valores participam de suas constituiçốes identitárias. O trabalho de campo foi desenvolvido em uma das unidades do Serviço Social e do Comércio (Sesc) do município do Rio de Janeiro, ao longo de um ano letivo completo, durante o qual foram feitos encontros semanais, de aproximadamente três horas, com as crianças e as professoras de uma turma de educação infantil.

2. Postman (1999), ao tratar do conceito moderno de infância, toma como referência as análises de Ariès (1981) sobre a reconstituição das representações e das práticas sociais para compor a história da infância no contexto europeu, desde a cultura medieval até a modernidade.

3. Ver Buckingham (2000).

4. Canal de tevê a cabo ou por assinatura.

5. Pode-se considerar que essa confusão quanto ao gênero da personagem é fortemente influenciada pelo nome que ela recebe na língua portuguesa, por sofrer variaçōes quanto ao gênero, o que já não acontece na língua inglesa, idioma original do desenho animado, no qual a mesma personagem recebe o nome de Buttercup, totalmente invariável.

6. Rita Marisa Pereira Ribes, professora da Universidade do Estado do Rio de Janeiro (Uerj), é a outra pesquisadora que, na ocasião, compartilhava comigo o trabalho de campo na mesma turma de crianças. Sua temática de pesquisa, porém, tratava das relações entre infância e publicidade.

7. Músicas de sucesso de Kelly Key e do grupo Rouge.

8. O conceito de cultura lúdica aqui mencionado é definido pelo autor como o conjunto de costumes lúdicos, regras, significações e brincadeiras, sejam estas individuais, coletivas e geracionais, que se realiza e participa da vida social mais ampla. 


\section{Referências}

ARIÈS, P. História social da criança e da família. 2. ed. Rio de Janeiro: Guanabara, 1981.

BAZALGETTE, C.; BUCKINGHAM, D. (Org.). In front of the children: screen entertainment and young audiences. London: British Film Institute, 1995.

BROUGÈRE, G. Brinquedo e cultura. São Paulo: Cortez, 1995.

BROUGÈRE, G. A criança e a cultura lúdica. In: KISHIMOTO, T.M. (Org.). O brincar e suas teorias. São Paulo: Pioneira, 1998. p. 19-32.

BUCKINGHAM, D. After the death of childhood: growing up in the age of electronic media. Cambridge: Polity Press, 2000.

BUCKINGHAM, D. (Org.). Small screens: television for children. London: Leicester University Press, 2002.

JAMESON, F. O pós-modernismo e a sociedade de consumo. In: KAPLAN, E.A. (Org.). O mal-estar no pós-modernismo: teorias, práticas. Rio de Janeiro: Zahar, 1993. p. 25-44.

KEHL, M.R. Lugares do feminino e do masculino na família. In: COMPARATO, M.C.M.; MONTEIRO, D.S.F. (Org.). A criança na contemporaneidade e a psicanálise: família e sociedade - Diálogos interdisciplinares. São Paulo: Casa do Psicólogo, 2001. p. 29-38.

LYOTARD, J-F. A condição pós-moderna. 5. ed. Rio de Janeiro: José Olympio, 1998.

MAYALL, B.; ZEIHER, H. (Org.). Childhood in generational perspective. London: Bedford Way Papers, 2003.

POSTMAN, N. O desaparecimento da infância. Rio de Janeiro: Graphia, 1999.

POTTS, D.L. Channeling girl power: positive female media images in "The Powerpuff Girls". Studies in media and information literacy education, v. 1, n. 4, 2001. Disponível em: <http://www.utpjournals.com/simile>. Acesso em: 10 mar. 2004. 
Da menina meiga à heroína superpoderosa...

SALGADO, R.G. "Eu tenho a força!": os super-heróis mirins nos desenhos animados e na vida. In: JOBIM E SOUZA, S. (Org.). Educação@pós-modernidade: ficções científicas e crônicas do cotidiano. Rio de Janeiro: 7 Letras, 2003. p. 75-87.

SCOTT, J. Gênero: uma categoria útil de análise histórica. Educação \& Realidade, Porto Alegre, v. 20, n. 2, p. 71-99, 1995.

STEINBERG, S.R.; KINCHELOE, J.L. Cultura infantil: a construção corporativa da infância. Rio de Janeiro: Civilização Brasileira, 2001 .

VYGOTSKY, L.S. Pensamento e linguagem. 3. ed. São Paulo: Martins Fontes, 1991.

WALKERDINE, V. Daddy's girl: young girls and popular culture. London: MacMillan Press, 1997.

Recebido em 10 de junho de 2009.

Aprovado em 20 de novembro de 2011. 